\title{
A comparative study of the effects of genistein, estradiol and raloxifene on the murine skeletal system ${ }^{\star}$
}

\author{
Leszek Śliwiński ${ }^{1}$, Joanna Folwarczna ${ }^{1 凶}$, Barbara Nowińska ${ }^{1}$, Urszula Cegieła1 ${ }^{1}$, Maria \\ Pytlik$^{1}$, Ilona Kaczmarczyk-Sedlak ${ }^{1}$, Hanna Trzeciak ${ }^{2}$ and Henryk I. Trzeciak ${ }^{1}$ \\ ${ }^{1}$ Department of Pharmacology, Medical University of Silesia, Katowice, Sosnowiec, Poland; ${ }^{2}$ Department of \\ Prosthetic Dentistry, Medical University of Silesia, Bytom, Poland
}

Received: 20 January, 2009; revised: 26 March, 2009; accepted: 24 April, 2009

available on-line: 30 April, 2009

\begin{abstract}
Genistein, a major phytoestrogen of soy, is considered a potential drug for prevention and treatment of postmenopausal osteoporosis. The aim of the present study was to compare the effects of genistein, estradiol and raloxifene on the skeletal system in vivo and in vitro. Genistein (5 $\mathrm{mg} / \mathrm{kg})$, estradiol $(0.1 \mathrm{mg} / \mathrm{kg})$ or raloxifene hydrochloride $(5 \mathrm{mg} / \mathrm{kg})$ were administered daily by a stomach tube to mature ovariectomized Wistar rats for 4 weeks. Bone mass, mineral and calcium content, macrometric parameters and mechanical properties were examined. Also the effects of genistein, estradiol and raloxifene $\left(10^{-9}-10^{-7} \mathrm{M}\right)$ on the formation of osteoclasts from neonatal mouse bone marrow cells and the activity of osteoblasts isolated from neonatal mouse calvariae were compared. In vivo, estrogen deficiency resulted in the impairment of bone mineralization and bone mechanical properties. Raloxifene but not estradiol or genistein improved bone mineralization. Estradiol fully normalized the bone mechanical properties, whereas genistein augmented the deleterious effect of estrogen-deficiency on bone strength. In vitro, genistein, estradiol and raloxifene inhibited osteoclast formation from mouse bone marrow cells, decreasing the ratio of RANKL mRNA to osteoprotegerin mRNA expression in osteoblasts. Genistein, but not estradiol or raloxifene, decreased the ratio of alkaline phosphatase mRNA to ectonucleotide pyrophosphatase phosphodiesterase $1 \mathrm{mRNA}$ expression in osteoblasts. This difference may explain the lack of genistein effect on bone mineralization observed in ovariectomized rats in the in vivo study. Concluding, our experiments demonstrated profound differences between the activities of genistein, estradiol and raloxifene towards the osseous tissue in experimental conditions.
\end{abstract}

Keywords: bone mechanical properties, bone mineralization, estradiol, genistein, osteoblasts, osteoclasts, raloxifene

\section{INTRODUCTION}

In recent years, isoflavones have received considerable attention as potential drugs for prevention and treatment of postmenopausal osteoporosis. Genistein, an isoflavone, is the major phytoestrogen of soybean and soy-based products. Phytoestrogens are a heterogeneous group of non-steroidal plantderived compounds that exhibit estrogen-like effects in estrogen target tissues, including bone (Viereck et al., 2002; Weaver \& Cheong, 2005).

Inhibitory effects of genistein on the osteoclast formation induced by different stimulatory factors (Amano et al., 1998; Gao \& Yamaguchi, 1999; Yamagishi et al., 2001; García Palacios et al., 2005; Śliwiński et al., 2005) and on osteoclast function (Blair et al., 1996; Williams et al., 1998; Gao \& Yamaguchi, 2000; Kajiya et al., 2000) have been reported. Genistein

${ }^{\square}$ Corresponding author: Joanna Folwarczna, Department of Pharmacology, Medical University of Silesia, Jagiellońska 4, 41-200 Sosnowiec, Poland; phone/fax: (48 32) 364 1540; e-mail: jfolwarczna@sum.edu.pl

^ Preliminary results of part of this study were presented during the 34th European Symposium on Calcified Tissues, 5-9 May, 2007, Copenhagen, Denmark.

Abbreviations: ALP, alkaline phosphatase; ENPP1, ectonucleotide pyrophosphatase phosphodiesterase 1; ER, estrogen receptor; GAPDH, glyceraldehyde-3-phosphate dehydrogenase; OPG, osteoprotegerin; RANKL, receptor activator of nuclear factor- $\mathrm{\kappa B}$ ligand; SERM, selective estrogen receptor modulator. 
was also reported to increase osteoblastic differentiation and affect osteoblast activity (Rickard et al., 2003; Pan et al., 2005; Morris et al., 2006; Okumura et al., 2006). Animal studies of isoflavones demonstrated contradictory results depending on animal species, age and duration of treatment (for reviews see: Migliaccio \& Anderson, 2003; Setchell \& LydekingOlsen, 2003). It has been suggested, but with no conclusive evidence, that isoflavones from the sources studied so far have a beneficial effect on bone health in postmenopausal women (Cassidy et al., 2006).

Although the effects of isoflavones on bone metabolism appear inconsistent in randomized clinical trials, recently performed meta-analysis suggested that isoflavones contribute significantly to inhibiting bone resorption and stimulating bone formation, especially in postmenopausal women (Ma et al., 2008). However, there are still no results of randomized clinical trials concerning the effects of soy isoflavones on the fracture risk, the critical end-point for all the treatments designed to prevent or treat osteoporosis (Migliaccio \& Anderson, 2003; Weaver \& Cheong, 2005). It is also not clear whether the mechanism of action of genistein on bone turnover is distinct from that of estradiol or raloxifene, a selective estrogen receptor modulator (SERM) used in the prevention and treatment of osteoporosis. The aim of the present study was to compare the effects of genistein, estradiol and raloxifene on the skeletal system in vivo, in estrogen-deficient rats, and in vitro (on the 1,25-dihydroxyvitamin $\mathrm{D}_{3}$-stimulated formation of murine osteoclasts and on mRNA expression in cultured murine osteoblasts).

\section{MATERIALS AND METHODS}

\section{In vivo experiments}

Experiments were carried out on mature (3month-old) female Wistar rats, obtained from the Center of Experimental Medicine, Medical University of Silesia. The rats were fed a standard diet ad libitum. The procedure of the experiments was approved by the Local Ethics Commission (Katowice, Poland).

The animals (body mass at the start of the experiment: $210-230 \mathrm{~g}$ ) were divided into five groups: I. Sham-operated control rats; II. Ovariectomized control rats; III. Ovariectomized rats receiving genistein (synthesized at the Pharmaceutical Research Institute, Warszawa, Poland) at a dose of $5 \mathrm{mg} / \mathrm{kg}$ daily; IV. Ovariectomized rats receiving estradiol (Estrofem, Novo Nordisk A/S) at a dose of $0.1 \mathrm{mg} /$ $\mathrm{kg}$ daily; V. Ovariectomized rats receiving raloxifene hydrochloride (Evista, Eli Lilly) at a dose of $5 \mathrm{mg} / \mathrm{kg}$ daily. The number of rats per group was 11 for the control groups (I and II) and 6 for groups treated with the drugs (III-V).

The drugs were administered by a stomach tube once daily for 4 weeks. The control rats received the vehicle $-0.25 \%$ water solution of carboxymethylcellulose in the same volume of $2 \mathrm{ml} / \mathrm{kg}$ daily.

Bilateral ovariectomy and sham-operation were performed 3 or 4 days before the start of administration of the investigated compounds.

After 4 weeks of drug administration, the animals were sacrificed and the tibia, femurs and L-4 vertebra were excised and immediately cleaned of soft tissues by cutting and scraping with surgical instruments. The left bones were weighed immediately after isolation (without drying or defatting), and their macrometric parameters were determined (length, diameter of the diaphysis in mid-length). The masses of the uterus and thymus were also determined.

Studies on bone mechanical properties. Bone mechanical properties were assessed using an apparatus constructed at the Department of Pharmacology, Medical University of Silesia, in cooperation with Hottinger Baldwin Messtechnik GmbH. The mechanical properties of the whole femur and femoral neck were examined as previously described (Folwarczna et al., 2004; Pytlik et al., 2004).

The mechanical properties of whole left femurs were studied using a bending test with threepoint loading. The load-deformation curves, obtained for each bone, representing the relationships between load applied to the bone and deformation in response to the load, were analyzed. Within the elastic deformation region, the slope of the load-deformation curve, representing the extrinsic stiffness of bone, was determined. Within the plastic deformation region, the ultimate load (maximum load sustained by the bone) and the deformation caused by the ultimate load were determined.

The mechanical properties of the femoral neck were studied using a compression test. The load was applied to the head of the femur along the long axis of the femur. The load causing fracture of the femoral neck was determined.

In order to determine the mass of mineral substances in bones, the L- 4 vertebra, left tibia and femur were mineralized (ashed) at the temperature of $640^{\circ} \mathrm{C}$ for $48 \mathrm{~h}$ in a muffle furnace and the ash was weighed. Calcium content in the mineralized bones was then determined colorimetrically, using a kit produced by Pointe Scientific Inc.

Statistical analysis. Results are presented as means \pm S.E.M. One-way ANOVA followed by Tukey's test was used for evaluation of statistical significance of the results. The results obtained in the 
ovariectomized control rats (group II) were compared with those of the sham-operated control rats (group I). The results obtained after administration of genistein, estradiol and raloxifene were compared with those of the ovariectomized control rats (group II).

\section{In vitro experiments}

Materials. MEM alpha medium without phenol red ( $\alpha$-MEM) (Gibco), Dulbecco's modified Eagle medium (DMEM) (Gibco), Dulbecco's phosphatebuffered saline (PBS) (Sigma), $1 \mathrm{M}$ Hepes buffer solution (Gibco), penicillin-streptomycin solution with 10000 units of penicillin and $10 \mathrm{mg}$ of streptomycin per millilitre in $0.9 \% \mathrm{NaCl}$ (Sigma), fetal bovine serum (FBS) (Gibco), 1 1 ,25-dihydroxycholecalciferol (Sigma), collagenase (Sigma), trypsin (Sigma), EDTA (Sigma), 0.25\% trypsin/EDTA solution (Sigma).

Drugs used: $\beta$-estradiol (Sigma), raloxifene hydrochloride and genistein, synthesized at the Pharmaceutical Research Institute (Warszawa, Poland).

PCR primers were purchased from the Institute of Biochemistry and Biophysics, Polish Academy of Sciences (Warszawa, Poland).

Osteoclast formation from murine bone marrow cells. Bone marrow cells from long bones of 5-7-day-old BALB/c mice (Center of Experimental Medicine, Medical University of Silesia) were obtained and cultured as previously described (Taranta $e t$ al., 2002). Long bones from neonatal mice were aseptically removed and dissected free of soft tissues. Bones were longitudinally sectioned and marrow cavities were flushed with DMEM containing $10 \%(\mathrm{v} / \mathrm{v})$ FBS and 1\% (v/v) penicillin/streptomycin solution, buffered with $10 \mathrm{mM}$ Hepes. The suspension containing bone fragments was pipetted to release the cells. After centrifugation at $250 \times g$ for $10 \mathrm{~min}$, pellet was resuspended in $\alpha$-MEM with $10 \%(\mathrm{v} / \mathrm{v})$ FBS and $1 \%(\mathrm{v} / \mathrm{v})$ penicillin/streptomycin solution. Bone marrow cells were then plated in 48well culture plates (Nunc) and incubated at $37^{\circ} \mathrm{C}$ in $5 \% \mathrm{CO}_{2}$ in humidified air. The next day after plating, the medium was replaced with fresh medium with addition of 1,25-dihydroxyvitamin $\mathrm{D}_{3}\left(10^{-8} \mathrm{M}\right)$ and the investigated compounds at concentrations of $10^{-9}, 10^{-8}$ or $10^{-7} \mathrm{M}$ (prepared from $1000 \times$ concentrated stock solutions in $99.8 \%$ ethanol).

The culture media were refreshed every second day. The cultures were ended 9 days after plating, fixed with $3 \%$ paraformaldehyde in $0.1 \mathrm{M}$ cacodylate buffer ( $\mathrm{pH}$ 7.2) and stained for tartrateresistant acid phosphatase (TRAP). TRAP staining was performed histochemically with a commercially available kit (Leucocyte acid phosphatase kit, Sigma Diagnostics, procedure 386). Large, multinucleated, TRAP-positive cells were considered osteoclasts.
Osteoclasts were counted and scored according to their diameter (below $100 \mu \mathrm{m}, 100-300 \mu \mathrm{m}$ and above $300 \mu \mathrm{m})$. The observations and measurements were made using an Eclipse TE 300 microscope (Nikon) connected through a digital camera (Nikon) to a personal computer (software: Nis-Elements 2.21, Nikon).

The results were obtained in three independent experiments.

Osteoblast isolation and culture. Osteoblastic cells were obtained and cultured as previously described (Luben \& Cohn, 1976). One-to-two dayold BALB/c mice (Center of Experimental Medicine, Medical University of Silesia) were killed, and their calvariae were aseptically isolated, dissected free of adhering soft tissues and washed in PBS. Osteoblasts were isolated from the calvariae by six sequential digestions (20 min each) with $0.1 \%$ collagenase and $0.05 \%$ trypsin. Osteoblastic cells collected from fractions 3-6 were combined and cultured in $\alpha$-MEM supplemented with $10 \%$ (v/v) FBS and $1 \%$ $(\mathrm{v} / \mathrm{v})$ penicillin/streptomycin solution. The cultures were maintained at $37^{\circ} \mathrm{C}$ in $5 \% \mathrm{CO}_{2}$ in humidified air. Medium was changed every 2-3 days. Subconfluent cultures were trypsinized and then replated at $10000 \mathrm{cells} / \mathrm{cm}^{2}$. The third passage cells were used for experiments.

mRNA expression in osteoblasts. Osteoblastic cells were plated in $25 \mathrm{~cm}^{2}$ bottles (Nunc) and cultured to $80-90 \%$ confluence. The medium was then replaced with fresh medium with addition of genistein, estradiol or raloxifene, used at concentrations of $10^{-9}, 10^{-8}$ and $10^{-7} \mathrm{M}$. After $48 \mathrm{~h}$ of culture, the cultures were trypsinized, and then total RNA was isolated using GenElute mammalian total RNA miniprep kit (Sigma) following the manufacturer's instructions.

Enhanced avian HS RT-PCR-100 kit (Sigma) was used for obtaining cDNA following the manufacturer's instructions. The cDNA of glyceraldehyde-3-phosphate dehydrogenase (GAPDH), $\alpha 2$ procollagen type I chain, receptor activator of nuclear factor- $\mathrm{\kappa} B$ ligand (RANKL), osteoprotegerin (OPG), alkaline phosphatase (ALP) and ectonucleotide pyrophosphatase phosphodiesterase 1 (ENPP1) were amplified using Taq DNA polymerase (ReadyMix REDTaq PCR reaction mix with $\mathrm{MgCl}_{2}$, Sigma). The PCR conditions are presented in Table 1.

The obtained PCR products were electrophoresed on a $1.5 \%$ agarose gel containing ethidium bromide and visualized under UV light. During the electrophoresis, the product of amplification of each cDNA was accompanied by the product of amplification of GAPDH cDNA and a DNA size standard. The image of the stained gel was analyzed semiquantitatively using Quantity One program (Bio-Rad Laboratories Inc). 
Table 1. Conditions of PCR.

\begin{tabular}{|c|c|c|c|c|c|}
\hline & Primers & $\begin{array}{l}\text { Number of } \\
\text { cycles }\end{array}$ & Denaturation & Annealing & Elongation \\
\hline${ }^{\mathrm{a}} \mathrm{GAPDH}$ & $\begin{array}{ll}5^{\prime}-\text { ACCACAGTCCATGCCATCAC-3' } & \text { (for) } \\
5^{\prime}-\text { TCCACCACCCTGTTGCTGTA-3' } & \text { (rev) } \\
\end{array}$ & 27 & $\begin{array}{l}95^{\circ} \mathrm{C} \\
1 \mathrm{~min}\end{array}$ & $\begin{array}{l}57^{\circ} \mathrm{C} \\
2 \mathrm{~min}\end{array}$ & $\begin{array}{l}72^{\circ} \mathrm{C} \\
2 \mathrm{~min}\end{array}$ \\
\hline $\begin{array}{l}\text { bProcollagen } \\
\text { type I }\end{array}$ & $\begin{array}{ll}5^{\prime} \text {-GCAATCGGGATCAGTACGAA-3' } & (\text { for }) \\
5^{\prime} \text {-CTTTCACGCCTTTGAAGCCA-3' } & (\text { rev }) \\
\end{array}$ & 28 & $\begin{array}{l}95^{\circ} \mathrm{C} \\
1 \mathrm{~min} \\
\end{array}$ & $\begin{array}{l}56^{\circ} \mathrm{C} \\
2 \mathrm{~min} \\
\end{array}$ & $\begin{array}{l}72^{\circ} \mathrm{C} \\
2 \mathrm{~min} \\
\end{array}$ \\
\hline aRANKL & $\begin{array}{ll}5^{\prime} \text {-CGCTCTGTTCCTGTACTTTCGAGCG-3' } & \text { (for) } \\
5^{\prime} \text {-TCGTGCTCCCTCCTTTCATCAGGTT-3' } & \text { (rev) } \\
\end{array}$ & 29 & $\begin{array}{l}95^{\circ} \mathrm{C} \\
1 \mathrm{~min} \\
\end{array}$ & $\begin{array}{l}57^{\circ} \mathrm{C} \\
2 \mathrm{~min} \\
\end{array}$ & $\begin{array}{l}72^{\circ} \mathrm{C} \\
2 \mathrm{~min} \\
\end{array}$ \\
\hline boPG & $\begin{array}{l}5^{\prime} \text {-AAAGCACCCTGTAGAAAACA-3' } \quad \text { (for) } \\
5^{\prime} \text {-CCGTTTTATCCTCTCTACACTC-3' } \quad(\text { rev })\end{array}$ & 30 & $\begin{array}{l}95^{\circ} \mathrm{C} \\
1 \mathrm{~min} \\
\end{array}$ & $\begin{array}{l}55^{\circ} \mathrm{C} \\
2 \mathrm{~min} \\
\end{array}$ & $\begin{array}{l}72^{\circ} \mathrm{C} \\
2 \mathrm{~min} \\
\end{array}$ \\
\hline${ }^{\mathrm{c}} \mathrm{ALP}$ & $\begin{array}{ll}5^{\prime} \text {-CCGTTCTTTCTCTATTC-3' } & \text { (for) } \\
5^{\prime} \text {-GCCACCCTGGGTAGACA-3' } & \text { (rev) } \\
\end{array}$ & 30 & $\begin{array}{l}95^{\circ} \mathrm{C} \\
1 \mathrm{~min} \\
\end{array}$ & $\begin{array}{l}54^{\circ} \mathrm{C} \\
2 \mathrm{~min} \\
\end{array}$ & $\begin{array}{l}72^{\circ} \mathrm{C} \\
2 \mathrm{~min} \\
\end{array}$ \\
\hline dENPP1 & $\begin{array}{l}5^{\prime}-\text { TCAGTACCATTTGAAGAAAGGATTTTAG- } \\
\text { CTGTTCT-3' (for) } \\
5^{\prime} \text {-GTCAGAGCCATGAAATCCACTTCCAC-3' (rev) }\end{array}$ & 31 & $\begin{array}{l}95^{\circ} \mathrm{C} \\
1 \mathrm{~min}\end{array}$ & $\begin{array}{l}65^{\circ} \mathrm{C} \\
2 \mathrm{~min}\end{array}$ & $\begin{array}{l}72^{\circ} \mathrm{C} \\
2 \mathrm{~min}\end{array}$ \\
\hline
\end{tabular}

${ }^{a}$ Li et al., 2002; b Taranta et al., 2002; 'Liu et al., 1998; dFarahbakhsh, 2003.

The results were expressed as the ratio of the integrated optical density of the investigated cDNA amplification product band to the integrated optical density of the GAPDH cDNA amplification product band and presented as the percentage of the mean value obtained for control cultures. The results were obtained in three independent experiments.

Statistical analysis. Results are presented as means \pm S.E.M. One-way ANOVA followed by Dunnett's test was used for evaluation of statistical significance of the results. The results obtained for cultures in the presence of genistein, estradiol or raloxifene were compared with those obtained for control cultures.

\section{RESULTS}

Effects of genistein, estradiol and raloxifene on the mass of uterus and thymus and body mass gain

The bilaterally ovariectomized rats were estrogen-deficient, as it was shown by substantial decreases in the uterus mass and increases in the thymus mass in relation to the sham-operated control rats (Table 2). In the ovariectomized control rats, the body mass gain was statistically significantly larger than in the sham-operated controls.

Estradiol significantly counteracted the effects of estrogen deficiency on the uterus and thymus mass; also raloxifene significantly decreased the thymus mass. Only raloxifene decreased the body mass gain of the ovariectomized rats.

\section{Effects of genistein, estradiol and raloxifene on bone mass and mineralization}

The deficiency of estrogens did not cause changes in the bone mass and the mass of bone mineral (not shown), but it statistically significantly decreased the ratio of mass of bone mineral to bone mass and the content of calcium in the bone mineral in comparison with the sham-operated rats (Figs. 1 and 2).

Only raloxifene increased bone mineralization in ovariectomized rats in relation to the ovariectomized control rats, since the ratio of bone mineral mass to bone mass was statistically significantly higher than in the ovariectomized control rats. Estradiol and genistein had no positive effects on bone mineralization. None of the treatments significantly affected the calcium content in the bone mineral.

Table 2. Effects of genistein, estradiol and raloxifene on the mass of uterus and thymus and body mass gain in ovariectomized rats.

\begin{tabular}{llllll}
\hline Parameter & $\begin{array}{l}\text { Sham-operated } \\
\text { control }\end{array}$ & OVX control & OVX + genistein & OVX + estradiol & OVX + raloxifene \\
\hline Body mass gain [g] & $15.18 \pm 1.49$ & $29.18 \pm 3.60^{* *}$ & $41.83 \pm 4.23$ & $26.67 \pm 1.73$ & $4.83 \pm 2.09^{\circ 00}$ \\
Uterus mass [g] & $0.443 \pm 0.035$ & $0.098 \pm 0.005^{* * *}$ & $0.101 \pm 0.006$ & $0.217 \pm 0.021^{\circ}$ & $0.118 \pm 0.015$ \\
Thymus mass [g] & $0.275 \pm 0.011$ & $0.529 \pm 0.021^{* * *}$ & $0.539 \pm 0.062$ & $0.444 \pm 0.025^{\circ}$ & $0.411 \pm 0.029^{\circ}$ \\
\hline
\end{tabular}

Results are presented as means \pm S.E.M. $(\mathrm{n}=6-11)$. Genistein $(5 \mathrm{mg} / \mathrm{kg})$, estradiol $(0.1 \mathrm{mg} / \mathrm{kg})$ or raloxifene hydrochloride $(5 \mathrm{mg} / \mathrm{kg})$ were administered daily for 4 weeks. Significant differences from sham-operated control rats: ${ }^{* *} P<0.01,{ }^{* * *} P<0.001$. Significant differences from ovariectomized control rats: ${ }^{\circ} P<0.05$, ${ }^{\circ o o} P<0.001$. 


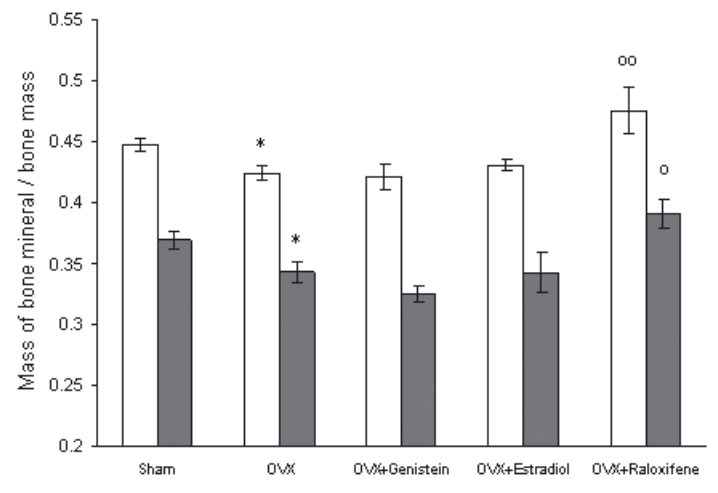

Figure 1. Effects of genistein, estradiol and raloxifene on the ratio of bone mineral mass to bone mass in ovariectomized rats.

Results are presented as means \pm S.E.M. $(n=6-11)$. Genistein $(5 \mathrm{mg} / \mathrm{kg})$, estradiol $(0.1 \mathrm{mg} / \mathrm{kg})$ or raloxifene hydrochloride $(5 \mathrm{mg} / \mathrm{kg}$ ) were administered daily for 4 weeks. Open bars, the ratio of bone mineral mass to bone mass in the tibia, and grey bars, the ratio of bone mineral mass to bone mass in the vertebra. Significant differences from sham-operated control rats: ${ }^{*} P<0.05$. Significant differences from ovariectomized control rats: ${ }^{\circ} P<0.05,{ }^{\circ} P<0.01$.

Effects of genistein, estradiol and raloxifene on bone mechanical properties

In the estrogen-deficient control rats, extrinsic stiffness of the femur was statistically significantly lower than in the sham-operated control rats (Table 3). The estrogen deficiency had no effect on the ultimate load sustained by the femur, but the deformation of the bone caused by the ultimate load was significantly higher.

After administration of estradiol to the ovariectomized rats, the extrinsic stiffness of the femur was fully normalized (statistically significant effect), and after administration of raloxifene it tended to be improved in comparison with the ovariectomized controls. In contrast, after administration of genistein, the extrinsic stiffness was statistically significantly decreased in relation to the ovariectomized control rats. Also the ultimate

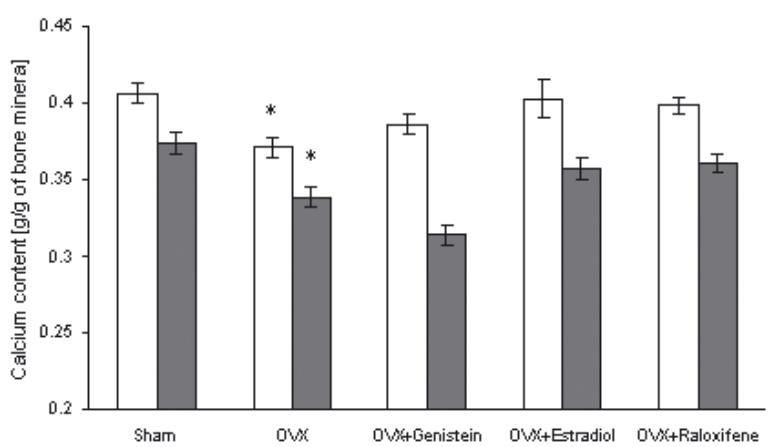

Figure 2. Effects of genistein, estradiol and raloxifene on the calcium content in the bone mineral of ovariectomized rats.

Results are presented as means \pm S.E.M. $(n=6-11)$. Genistein $(5 \mathrm{mg} / \mathrm{kg})$, estradiol $(0.1 \mathrm{mg} / \mathrm{kg})$ or raloxifene hydrochloride $(5 \mathrm{mg} / \mathrm{kg})$ were administered daily for 4 weeks. Open bars, calcium content in the tibia, and grey bars, calcium content in the vertebra. Significant differences from shamoperated control rats: ${ }^{*} P<0.05$.

load of the femur in rats receiving genistein was lower than in the sham-operated and ovariectomized control rats or in rats treated with estradiol or raloxifene.

A similar tendency could be observed in the femoral neck of the ovariectomized rats, where estradiol and raloxifene tended to increase its strength (determined by the load at fracture), whereas genistein tended to weaken it in relation to the ovariectomized control rats.

\section{Effects of genistein, estradiol and raloxifene on the formation of osteoclasts in vitro}

All the investigated compounds $\left(10^{-9}-10^{-7}\right.$ $\mathrm{M})$ inhibited the formation of osteoclasts in murine bone marrow cell cultures, with the maximum effect at $10^{-8} \mathrm{M}$ (Figs. 3 and 4 ). When the number of osteoclasts formed was analysed according to their size, very similar patterns of dose-response relationships

Table 3. Effects of genistein, estradiol and raloxifene on bone mechanical properties in ovariectomized rats.

\begin{tabular}{llllll}
\hline Parameter & $\begin{array}{l}\text { Sham-operated } \\
\text { control }\end{array}$ & OVX control & OVX + genistein & OVX + estradiol & OVX + raloxifene \\
\hline $\begin{array}{l}\text { Extrinsic stiffness of } \\
\text { femur [N/mm] }\end{array}$ & $210.37 \pm 5.57$ & $190.89 \pm 7.42^{*}$ & $159.03 \pm 4.80^{\circ}$ & $213.76 \pm 7.57^{\circ}$ & $201.03 \pm 6.92$ \\
$\begin{array}{l}\text { Ultimate load of femur } \\
{[\mathrm{N}]}\end{array}$ & $76.31 \pm 1.99$ & $75.95 \pm 2.55$ & $68.07 \pm 3.38$ & $78.64 \pm 2.26$ & $78.12 \pm 2.07$ \\
$\begin{array}{l}\text { Deformation caused by } \\
\text { ultimate load [mm] }\end{array}$ & $0.445 \pm 0.008$ & $0.485 \pm 0.011^{*}$ & $0.484 \pm 0.026$ & $0.447 \pm 0.013$ & $0.383 \pm 0.029^{\circ \circ}$ \\
$\begin{array}{l}\text { Load at fracture of } \\
\text { femoral neck [N] }\end{array}$ & $77.65 \pm 2.81$ & $73.95 \pm 1.72$ & $69.30 \pm 3.45$ & $81.66 \pm 6.39$ & $83.68 \pm 3.79$ \\
\hline
\end{tabular}

Results are presented as means \pm S.E.M. $(\mathrm{n}=6-11)$. Genistein $(5 \mathrm{mg} / \mathrm{kg})$, estradiol $(0.1 \mathrm{mg} / \mathrm{kg})$ or raloxifene hydrochloride $(5 \mathrm{mg} / \mathrm{kg})$ were administered daily for 4 weeks. Significant differences from sham-operated control rats: ${ }^{*} P<0.05$. Significant differences from ovariectomized control rats: ${ }^{\circ} \mathrm{P}<0.05$; ${ }^{\circ} \mathrm{P}<0.01$. 


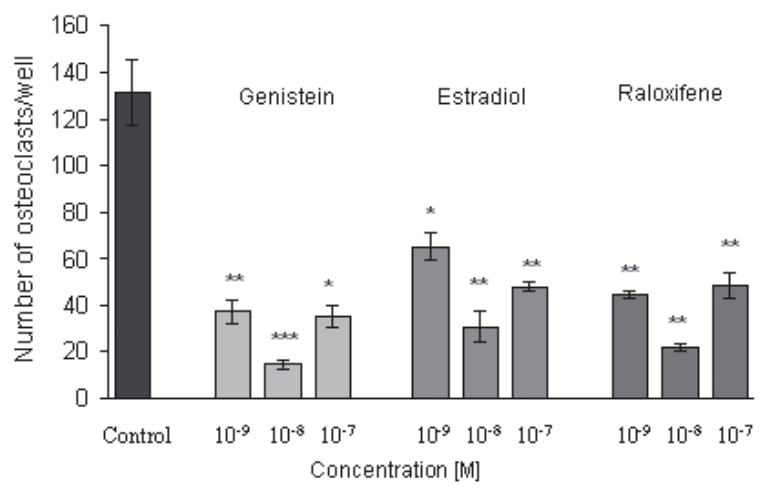

Figure 3. Effects of genistein, estradiol and raloxifene on number of osteoclasts formed in mouse bone marrow cell cultures in vitro.

Results are presented as means \pm S.E.M. $(n=3)$. Significant differences from controls: ${ }^{*} P<0.05,{ }^{* *} P<0.01$, ${ }^{* * *} P<0.001$.

were observed in the presence of genistein, estradiol and raloxifene in the culture media (not shown).

Effects of genistein, estradiol and raloxifene on the mRNA expression in osteoblasts in vitro

The obtained PCR product sizes were: $443 \mathrm{~kb}$ for GAPDH, $464 \mathrm{~kb}$ for procollagen type I, $570 \mathrm{~kb}$ for RANKL, $265 \mathrm{~kb}$ for OPG, $470 \mathrm{~kb}$ for ALP and $564 \mathrm{~kb}$ for ENPP1.

All the investigated compounds $\left(10^{-9}-10^{-7}\right.$ M) decreased the ratio of RANKL mRNA to OPG mRNA expression (Fig. 5). Estradiol tended to decrease the ratio by increasing the OPG mRNA expression and raloxifene decreased it by decreasing the RANKL mRNA expression. Genistein decreased the ratio by both increasing the OPG mRNA and by decreasing the RANKL mRNA expression.

Estradiol and raloxifene tended to decrease the collagen mRNA expression, whereas genistein had no such effect (not shown).

Genistein decreased the ratio of ALP mRNA to ENPP1 mRNA expression in murine osteoblasts (statistically significantly at $10^{-8} \mathrm{M}$ ), whereas estradiol and raloxifene tended to increase the ratio (Fig. 6).

\section{DISCUSSION}

The decrease of estrogen level in postmenopausal women results in an increased rate of bone turnover with bone resorption exceeding bone formation, leading to a general loss of bone mass and development of postmenopausal osteoporosis (Riggs, 1991). The incidence of osteoporosis-related fracture is significantly lower in Southern and Eastern Asian women than in Western women; one possible expla-
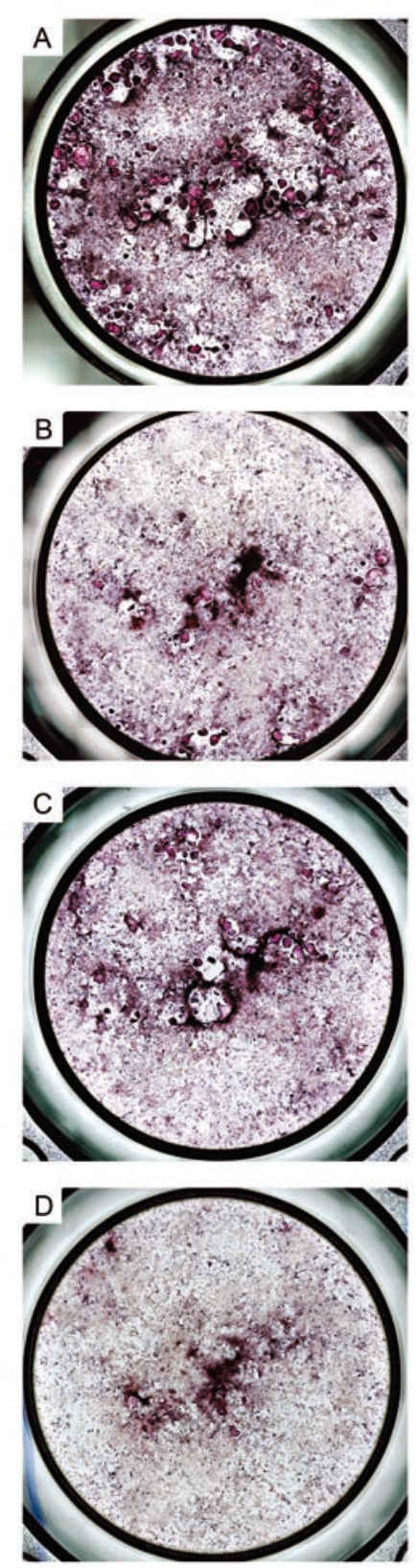

Figure 4. Effects of genistein, estradiol and raloxifene $\left(10^{-8} \mathrm{M}\right)$ on osteoclast formation in mouse bone marrow cell cultures in vitro.

Representative cultures are shown. From the top: control culture (A), and cultures conducted in the presence of genistein (B), estradiol (C) and raloxifene (D).

nation for this difference is a high intake of phytoestrogens (as Asian people consume soy 10-20 times more than Western people) (Ma et al., 2008). The main soy isoflavones are genistein and daidzein; both of them are considered potential therapeutics (Migliaccio \& Anderson, 2003; Setchell \& LydekingOlsen, 2003; Mathey et al., 2007; Om \& Shim, 2007). The value of genistein as a potential antiosteoporotic drug still needs to be established (Weaver \& Cheong, 2005; Cassidy et al., 2006). 

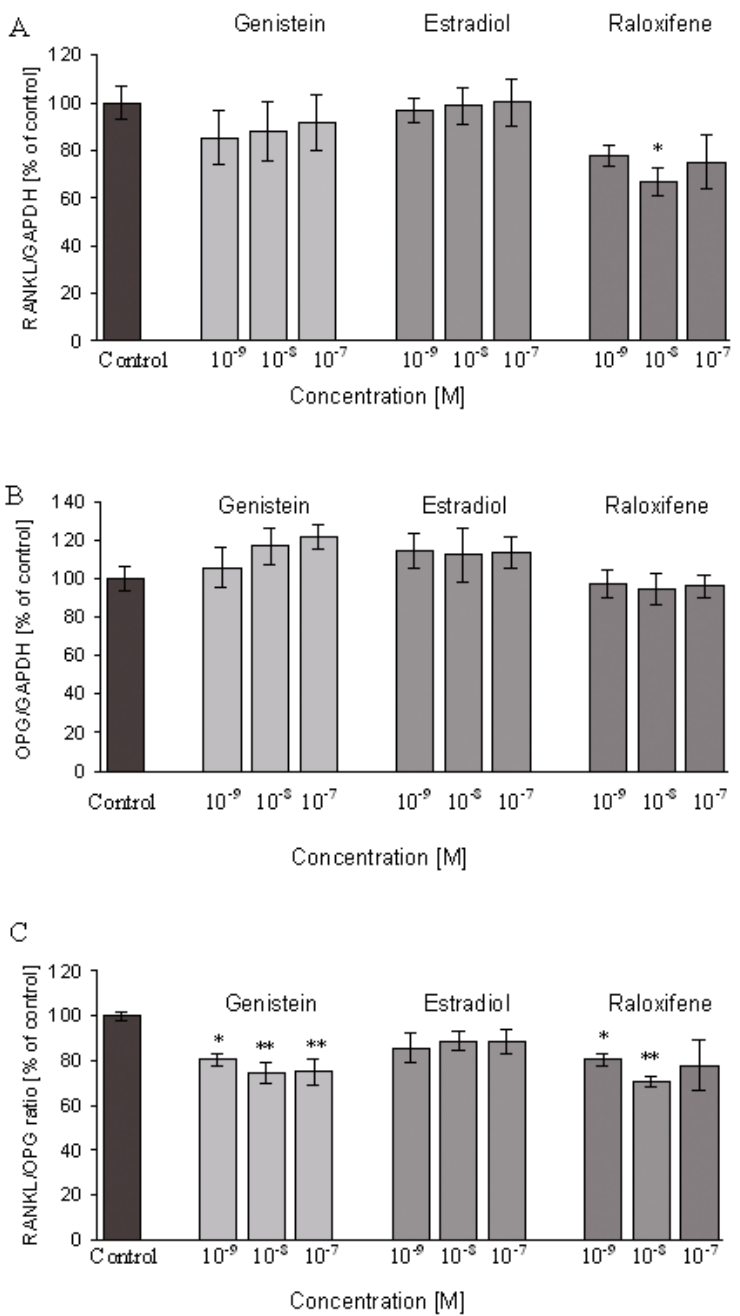

Figure 5. Effects of genistein, estradiol and raloxifene on the mRNA expression of factors affecting bone resorption in mouse osteoblasts in vitro.

Panel A: receptor activator of nuclear factor- $\kappa \mathrm{B}$ ligand (RANKL) mRNA expression, panel B: osteoprotegerin (OPG) mRNA expression, panel C: the ratio of RANKL mRNA to OPG mRNA expression. Results are presented as means \pm S.E.M. $(n=3)$. Significant differences from the controls: ${ }^{*} P<0.05,{ }^{* *} P<0.01$.

Estrogens regulate skeletal homeostasis in men and women. Estrogen effects are mediated via interactions with two estrogen receptor subtypes, $\alpha$ and $\beta$ (ER $\alpha$ and ER $\beta$ ). Both ER $\alpha$ and ER $\beta$ are present in bones. There are experimental data suggesting that ER $\alpha$ mediates estrogen-stimulated net increase in bone formation, while the ER $\beta$ 's role in bone is less clear (Deroo \& Korach, 2006). Some studies suggest that the effects of estrogen signaling through ER $\alpha$ and ER $\beta$ are opposite, while according to other reports activation of ER $\alpha$ and ER $\beta$ has similar effects on bone (Raisz, 2005). Estrogens, SERMs and phytoestrogens have different clinical profiles, differentially regulating the transcriptional activities of ER $\alpha$ and ER $\beta$. Estradiol is a

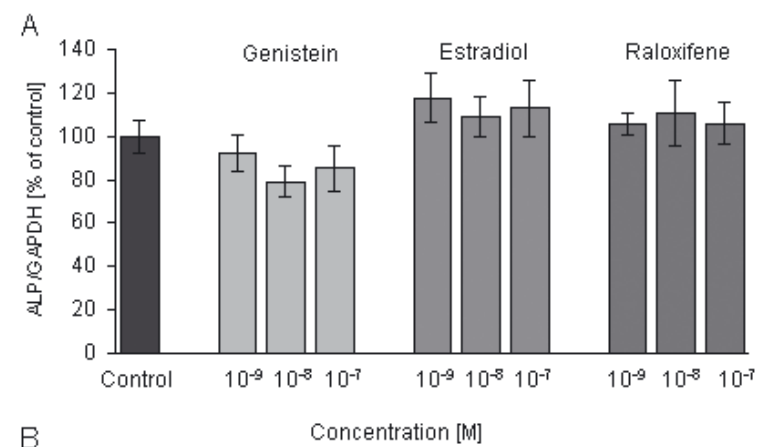

$\mathrm{B}$

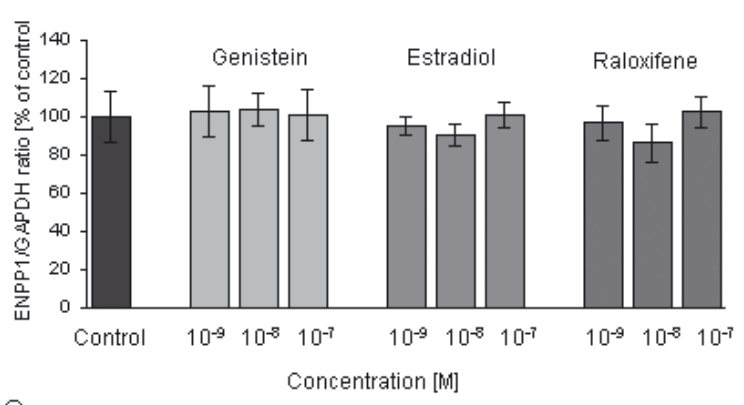

C

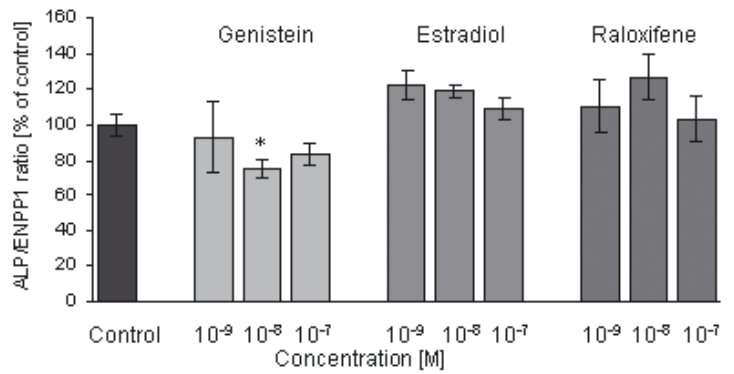

Figure 6. Effects of genistein, estradiol and raloxifene on the mRNA expression of enzymes involved in bone mineralization in mouse osteoblasts in vitro.

Panel A: alkaline phosphatase (ALP) mRNA expression, panel B: ectonucleotide pyrophosphatase phosphodiesterase 1 (ENPP1) mRNA expression, panel C: the ratio of ALP mRNA to ENPP1 mRNA expression. Results are presented as means \pm S.E.M. $(n=3)$. Significant differences from the controls: ${ }^{*} P<0.05$.

full agonist in all tissues because it nonselectively binds to ER $\alpha$ and ER $\beta$. SERMs exert antagonistic activity in some tissues and agonistic activity in others (Baker et al., 2000). Raloxifene has an ER $\alpha$ selective partial agonist/antagonist function but a pure antagonist effect through ER $\beta$. Genistein has a significantly higher affinity (and potency) for $E R \beta$ than $E R \alpha$, although it is only a partial agonist of ER $\beta$ and a full agonist of ER $\alpha$ (Barkhem et al., 1998). It has been proposed that genistein's agonist activity for ER $\beta$ mediates its health benefits (McCarty, 2006).

Besides having estrogen-like properties, genistein exhibits numerous biological actions, which could contribute to its biological effects on bone 
cells by ER-independent mechanisms. Genistein is a well-known protein tyrosine kinase inhibitor, it has also been reported to inhibit DNA topoisomerase II, cell cycle progression, angiogenesis, and oxidation reactions (Polkowski \& Mazurek, 2000; Migliaccio \& Anderson, 2003). However, it seems that the skeletal effects of genistein should be attributed to its binding to estrogen receptors, because activation of ERs is the only effect of genistein that has been documented in the low nanomolar range. These concentrations are far too low to inhibit tyrosine kinases or topoisomerase II (McCarty, 2006).

To compare the effects of genistein, estradiol and raloxifene in vivo, in the present study we used the model of bilaterally ovariectomized rats, which mimics the accelerated bone loss observed in postmenopausal women due to estrogen deficiency. This is a classical animal model for postmenopausal bone loss. The characteristics of skeletal physiology in this rat model share similarities with those of early postmenopausal women: an increased rate of bone turnover with resorption exceeding formation, and greater loss of cancellous than cortical bone (Kalu, 1991; Wronski \& Yen, 1991).

In our rat study, genistein was used at the dose of $5 \mathrm{mg} / \mathrm{kg}$, about ten times higher than the daily intake in Asian populations, where the estimated genistein consumption is approx. $0.4-0.6 \mathrm{mg} / \mathrm{kg}$ per day. Followers of strict vegetarian diets would be expected to have intake levels approaching that of the Asian diet. The typical Western diet contains far lower levels of genistein (Soucy et al., 2006). Genistein has been reported to have biphasic effects on the skeletal system of rats, with higher doses being less effective than lower ones (Reinwald \& Weaver, 2006). However, the dose used in the present study was within the range of doses reported to favourably affect the skeletal system of ovariectomized rats (Setchell \& Lydeking-Olsen, 2003). Safety studies of genistein in rats have estimated the no observed adverse effect level to be $50 \mathrm{mg} / \mathrm{kg}$ per day (McClain et al., 2006). We used a rather low dose of estradiol in the present study in order to obtain moderate effects comparable with those of genistein. Raloxifene was administered at a dose of the effective dose range used by others in ovariectomized rats (Evans et al., 1996).

In our experiment, as it was observed by others for genistein or soy extracts, genistein did not stimulate the uterus (Erlandsson et al., 2005; Mathey et al., 2007) and did not affect the body mass gain of ovariectomized animals (Gallo et al., 2005; Mathey et al., 2007).

The most interesting finding of our in vivo experiments is that genistein, in contrast to estradiol and raloxifene, did not favourably affect bone mineralization or mechanical properties, significantly worsened by estrogen deficiency in ovariectomized rats. In fact, genistein augmented the deleterious effect of estrogen deficiency on bone strength.

To elucidate the possible mechanism(s) of the observed differences in the mode of action of the investigated estrogenic compounds, we performed in vitro studies on murine bone cells. Such an approach has limitations, as it is not always possible to directly compare the results obtained in different species (rats and mice, not to mention humans). Also the artificial conditions of the cell culture should make one cautious in the interpreting of the obtained results. However, we made some new observations which may be of some value.

In the present study, genistein, estradiol and raloxifene similarly, strongly, inhibited osteoclast formation in murine bone marrow cell culture, with the maximum effect at $10^{-8} \mathrm{M}$. The inhibitory effect on osteoclast formation is consistent with our in vivo observations and with previous reports (Amano et al., 1998; Gao \& Yamaguchi, 1999; Yamagishi et al., 2001; García Palacios et al., 2005; Śliwiński et al., 2005). In contrast to our study, genistein $\left(3 \times 10^{-6} \mathrm{M}\right)$ inhibited osteoclastic differentiation in RAW264.7 cells (a murine monocytic cell line) in response to RANKL and M-CSF less effectively than did estradiol $\left(10^{-8}\right.$ M) (García Palacios et al., 2005). The observed similar effects of genistein, estradiol and raloxifene on osteoclast formation from bone marrow cells could be due to a similar net effect on the production of factors affecting osteoclastogenesis in bone marrow stromal/osteoblastic cells. The RANKL to OPG ratio is the key regulatory determinant of bone resorption (Kryśkiewicz \& Lorenc, 2006). All the investigated compounds (estradiol, raloxifene and genistein) decreased the ratio of RANKL mRNA to OPG mRNA expression in murine osteoblasts, which is consistent with previous reports (Hofbauer et al., 2004). However, some differences in the mechanisms engaged in the regulation of osteoclast formation could exist. In our study, the decreased ratio of RANKL mRNA to OPG mRNA expression in murine osteoblasts was due to an increase in the OPG mRNA expression in the case of estradiol and to a decrease in the RANKL mRNA expression in the case of raloxifene, whereas genistein increased the OPG mRNA and decreased the RANKL mRNA expression. This effect of genistein is consistent with the results obtained in clonal osteogenic stromal ST2 cells (Yamagishi et al., 2001). An increased OPG mRNA expression caused by genistein was also observed in human osteoblastic cells (Chen et al., 2002; Viereck et al., 2002).

Results of the in vitro studies indicating inhibition of osteoclastogenesis are consistent with our histomorphometric data from the study, not presented here. All the investigated compounds increased the trabeculae width in femoral epiphysis and tend- 
ed to decrease the ratio of the transverse cross-section area of the marrow cavity to the diaphysis area in the tibia. Taken together, our in vivo and in vitro studies confirmed previous observations that genistein, similarly to estradiol and raloxifene, inhibits bone resorption in experimental conditions.

To investigate the mechanisms responsible for the differential effects of genistein, estradiol and raloxifene on bone mineralization, their influence on the expression of alkaline phosphatase and ectonucleotide pyrophosphatase phosphodiesterase 1 mRNA in murine osteoblasts was studied. Osteoblasts mineralize bone matrix by promoting the formation and growth of hydroxyapatite crystals. Two osteoblast enzymes, tissue-nonspecific alkaline phosphatase (ALP) and ectonucleotide pyrophosphatase phosphodiesterase 1 (ENPP1, also called plasma cell membrane glycoprotein-1) are involved in this process, regulating the extracellular inorganic pyrophosphate $(\mathrm{PPi})$ concentration. $\mathrm{PPi}$, produced by ENPP1, has an inhibitory effect on hydroxyapatite deposition. ALP has a positive effect on mineralization primarily by controlling the size of the inhibitory pool of PPi through its inorganic pyrophosphatase activity. ALP also contributes to the pool of inorganic phosphate $(\mathrm{Pi})$ available for deposition as hydroxyapatite, generating $\mathrm{Pi}$ by using nucleoside triphosphates and PPi as substrates (Hessle et al., 2002; Harmey et al., 2004).

So far there are no reports on the effect of genistein on ENPP1 activity. The effects of genistein on ALP activity in osteoblasts have been reported to be stimulatory or inhibitory, probably depending on the type of osteoblastic cells used, or conditions of experiments (Morris et al., 2006). Generally, genistein was reported to exert stimulatory effects on bone mineralization in vitro (Pan et al., 2005; Morris et al., 2006). Genistein affected the ratio of ALP mRNA to ENPP1 mRNA expression in a different way than did estradiol and raloxifene. Genistein decreased the ratio, whereas estradiol and raloxifene tended to increase it. This difference, indicating that genistein may increase the pool of $\mathrm{PPi}$, may explain the lack of genistein effect on bone mineralization observed in ovariectomized rats in our in vivo study.

Concluding, our experiments have demonstrated profound differences between the activities of genistein, estradiol and raloxifene towards osseous tissue in experimental conditions. The most important difference was the lack of favourable effects of genistein on bone mineralization and mechanical properties in estrogen-deficient rats, which could be the result of its effects on osteoblastic expression of enzymes engaged in bone mineralization.

\section{Acknowledgements}

Genistein and raloxifene hydrochloride in substantia were a generous gift of Professor Grzegorz Grynkiewicz, Pharmaceutical Research Institute, Warszawa, Poland.

This study was supported by grant 2 P05D 09230 from the Ministry of Science and Higher Education, Poland.

\section{REFERENCES}

Amano H, Yamada S, Felix R (1998) Colony-stimulating factor-1 stimulates the fusion process in osteoclasts. $J$ Bone Miner Res 13: 846-853.

Baker VL, Leitman D, Jaffe RB (2000) Selective estrogen receptor modulators in reproductive medicine and biology. Obstet Gynecol Surv 55 (Suppl 2): S21-S47.

Barkhem T, Carlsson B, Nilsson Y, Enmark E, Gustafsson JA, Nilsson S (1998) Differential response of estrogen receptor $\alpha$ and estrogen receptor $\beta$ to partial estrogen agonists/antagonists. Mol Pharmacol 54: 105-112.

Blair HC, Jordan SE, Peterson TG, Barnes S (1996) Variable effects of tyrosine kinase inhibitors on avian osteoclastic activity and reduction of bone loss in ovariectomized rats. J Cell Biochem 61: 629-637.

Cassidy A, Albertazzi P, Lise-Nielsen I, Hall W, Williamson G, Tetens I, Atkins S, Cross H, Manios Y, Wolk A, Steiner C, Branca F (2006) Critical review of health effects of soyabean phyto-oestrogens in post-menopausal women. Proc Nutr Soc 65: 76-92.

Chen XW, Garner SC, Anderson JJ (2002) Isoflavones regulate interleukin-6 and osteoprotegerin synthesis during osteoblast cell differentiation via an estrogen-receptordependent pathway. Biochem Biophys Res Commun 295: 417-422.

Deroo BJ, Korach KS (2006) Estrogen receptors and human disease. J Clin Invest 116: 561-570.

Erlandsson MC, Islander U, Moverare S, Ohlsson C, Carlsten $\mathrm{H}$ (2005) Estrogenic agonism and antagonism of the soy isoflavone genistein in uterus, bone and lymphopoiesis in mice. APMIS 113: 317-323.

Evans GL, Bryant HU, Magee DE, Turner RT (1996) Raloxifene inhibits bone turnover and prevents further cancellous bone loss in adult ovariectomized rats with established osteopenia. Endocrinology 137: 4139-4144.

Farahbakhsh NA (2003) Ectonucleotidases of the rabbit ciliary body nonpigmented epithelium. Invest Ophthalmol Vis Sci 44: 3952-3960.

Folwarczna J, Janiec W, Śliwiński L (2004) Effects of heparin and low-molecular-weight heparins on bone mechanical properties in rats. Thromb Haemost 92: 940946.

Gallo D, Zannoni GF, Apollonio P, Martinelli E, Ferlini C, Passetti G, Riva A, Morazzoni P, Bombardelli E, Scambia $G$ (2005) Characterization of the pharmacologic profile of a standardized soy extract in the ovariectomized rat model of menopause: effects on bone, uterus, and lipid profile. Menopause 12: 589-600.

Gao YH, Yamaguchi M (1999) Inhibitory effect of genistein on osteoclast-like cell formation in mouse marrow cultures. Biochem Pharmacol 58: 767-772.

Gao YH, Yamaguchi M (2000) Suppressive effect of genistein on rat bone osteoclasts: involvement of protein 
kinase inhibition and protein tyrosine phosphatase activation. Int J Mol Med 5: 261-267.

García Palacios V, Robinson LJ, Borysenko CW, Lehmann T, Kalla SE, Blair HC (2005) Negative regulation of RANKL-induced osteoclastic differentiation in RAW264.7 cells by estrogen and phytoestrogens. J Biol Chem 280: 13720-13727.

Harmey D, Hessle L, Narisawa S, Johnson KA, Terkeltaub R, Millán JL (2004) Concerted regulation of inorganic pyrophosphate and osteopontin by Akp2, Enpp1, and $A n k$ : an integrated model of the pathogenesis of mineralization disorders. Am J Pathol 164: 1199-1209.

Hessle L, Johnson KA, Anderson HC, Narisawa S, Sali A, Goding JW, Terkeltaub R, Millán JL (2002) Tissue-nonspecific alkaline phosphatase and plasma cell membrane glycoprotein-1 are central antagonistic regulators of bone mineralization. Proc Natl Acad Sci USA 99: 9445-9449.

Hofbauer LC, Kühne CA, Viereck V (2004) The OPG/RANKL/RANK system in metabolic bone diseases. J Musculoskelet Neuronal Interact 4: 268-275.

Kajiya H, Okabe K, Okamoto F, Tsuzuki T, Soeda H (2000) Protein tyrosine kinase inhibitors increase cytosolic calcium and inhibit actin organization as resorbing activity in rat osteoclasts. J Cell Physiol 183: 83-90.

Kalu DN (1991) The ovariectomized rat model of postmenopausal bone loss. Bone Miner 15: 175-191.

Kryśkiewicz E, Lorenc RS (2006) RANKL/RANK/OPG system and its importance in bone physiology and pathophysiology. Terapia 3: 58-63.

Li X, Udagawa N, Itoh K, Suda K, Murase Y, Nishihara T, Suda T, Takahashi N (2002) p38 MAPK-mediated signals are required for inducing osteoclast differentiation but not for osteoclast function. Endocrinology 143: 3105-3113.

Liu BY, Guo J, Lanske B, Divieti P, Kronenberg HM, Bringhurst FR (1998) Conditionally immortalized murine bone marrow stromal cells mediate parathyroid hormone-dependent osteoclastogenesis in vitro. Endocrinology 139: 1952-1964.

Luben RA, Cohn DV (1976) Effects of parathormone and calcitonin on citrate and hyaluronate metabolism in cultured bone. Endocrinology 98: 413-419.

Ma DF, Qin LQ, Wang PY, Katoh R (2008) Soy isoflavone intake inhibits bone resorption and stimulates bone formation in menopausal women: meta-analysis of randomized controlled trials. Eur J Clin Nutr 62: 155-161.

Mathey J, Mardon J, Fokialakis N, Puel C, Kati-Coulibaly S, Mitakou S, Bennetau-Pelissero C, Lamothe V, Davicco MJ, Lebecque P, Horcajada MN, Coxam V (2007) Modulation of soy isoflavones bioavailability and subsequent effects on bone health in ovariectomized rats: the case for equol. Osteoporos Int 18: 671-679.

McCarty MF (2006) Isoflavones made simple - genistein's agonist activity for the beta-type estrogen receptor mediates their health benefits. Med Hypotheses 66: 1093-1114.

McClain RM, Wolz E, Davidovich A, Pfannkuch F, Edwards JA, Bausch J (2006) Acute, subchronic and chronic safety studies with genistein in rats. Food Chem Toxicol 44: 56-80.

Migliaccio S, Anderson JJ (2003) Isoflavones and skeletal health: are these molecules ready for clinical application? Osteoporos Int 14: 361-368.

Morris C, Thorpe J, Ambrosio L, Santin M (2006) The soybean isoflavone genistein induces differentiation of MG63 human osteosarcoma osteoblasts. J Nutr 136: 1166-1170.
Okumura N, Yoshikawa T, Iida J, Nonomura A, Takakura Y (2006) Bone formation-promoting effect of genistein on marrow mesenchymal cell culture. Biomed Mater Eng 16: 23-32.

Om A-S, Shim J-Y (2007) Effect of daidzein, a soy isoflavone, on bone metabolism in Cd-treated ovariectomized rats. Acta Biochim Polon 54: 641-646.

Pan W, Quarles LD, Song LH, Yu YH, Jiao C, Tang HB, Jiang CH, Deng HW, Li YJ, Zhou HH, Xiao ZS (2005) Genistein stimulates the osteoblastic differentiation via NO/cGMP in bone marrow culture. J Cell Biochem 94: 307-316.

Polkowski K, Mazurek AP (2000) Biological properties of genistein. A review of in vitro and in vivo data. Acta Pol Pharm 57: 135-155.

Pytlik M, Folwarczna J, Janiec W (2004) Effects of doxycycline on mechanical properties of bones in rats with ovariectomy-induced osteopenia. Calcif Tissue Int 75: 225-230.

Reinwald S, Weaver CM (2006) Soy isoflavones and bone health: a double-edged sword? J Nat Prod 69: 450-459.

Raisz LG (2005) Pathogenesis of osteoporosis: concepts, conflicts, and prospects. J Clin Invest 115: 3318-3325.

Rickard DJ, Monroe DG, Ruesink TJ, Khosla S, Riggs BL, Spelsberg TC (2003) Phytoestrogen genistein acts as an estrogen agonist on human osteoblastic cells through estrogen receptors $\alpha$ and $\beta$. J Cell Biochem 89: 633-646.

Riggs BL (1991) Overview of osteoporosis. West J Med 154: 63-77.

Setchell KDR, Lydeking-Olsen E (2003) Dietary phytoestrogens and their effect on bone: evidence from in vitro and in vivo, human observational, and dietary intervention studies. Am J Clin Nutr 78 (3 Suppl): 593S-609S.

Soucy NV, Parkinson HD, Sochaski MA, Borghoff SJ (2006) Kinetics of genistein and its conjugated metabolites in pregnant Sprague-Dawley rats following single and repeated genistein administration. Toxicol Sci 90: 230240.

Śliwiński L, Folwarczna J, Janiec W, Grynkiewicz G, Kuzyk K (2005) Differential effects of genistein, estradiol and raloxifene on rat osteoclasts in vitro. Pharmacol Rep 57: 352-359.

Taranta A, Brama M, Teti A, De Luca V, Scandurra R, Spera G, Agnusdei D, Termine JD, Migliaccio S (2002) The selective estrogen receptor modulator raloxifene regulates osteoclast and osteoblast activity in vitro. Bone 30: 368-376.

Viereck V, Gründker C, Blaschke S, Siggelkow H, Emons G, Hofbauer LC (2002) Phytoestrogen genistein stimulates the production of osteoprotegerin by human trabecular osteoblasts. J Cell Biochem 84: 725-735.

Weaver CM, Cheong JM (2005) Soy isoflavones and bone health: the relationship is still unclear. J Nutr 135: 1243-1237.

Williams JP, Jordan SE, Barnes S, Blair HC (1998) Tyrosine kinase inhibitor effects on avian osteoclastic acid transport. Am J Clin Nutr 68 (6 Suppl): 1369S-1374S.

Wronski TJ, Yen C-F (1991) The ovariectomized rat as an animal model for postmenopausal bone loss. Cells $M a$ terials Suppl 1: 69-74.

Yamagishi T, Otsuka E, Hagiwara H (2001) Reciprocal control of expression of mRNAs for osteoclast differentiation factor and OPG in osteogenic stromal cells by genistein: evidence for the involvement of topoisomerase II in osteoclastogenesis. Endocrinology 142: 3632-3637. 